\title{
Pelatihan UMKM Berbasis Online di Kantor Pemerintahan Desa Lambangsari Kecamatan Tambun Selatan Kabupaten Bekasi
}

\author{
${ }^{1 *}$ Destiana Kumala, ${ }^{2}$ Taufik Hidayat \\ STEBIS Bina Mandiri, Bogor, Indonesia \\ *destiana.kumala86@gmail.com
}

\begin{abstract}
Abstrak
Artikel pengabdian masyarakat ini membahas tentang proses kegiatan pelatihan UMKM berbasis online di kantor pemerintahan Desa Lambangsari. Pelaksanaan kegiatan Pelatihan UMKM Berbasis Online ini dihadiri 30 (tiga puluh) Peserta, bertempat di Kantor Pemerintahan Desa Lambangsari Kecamatan Tambun Selatan Kabupaten Bekasi. Pelaksanaan ini diadakan dengan protokol kesehatan Covid-19. Adapun tema yang di usung dalam pelatihan ini adalah “UMKM Naik Kelas". Metode yang di gunakan dalam pelatihan ini adalah pertama Persiapan dan Sosialisasi, yaitu dengan pemberian materi oleh pembicara, kedua Pelatihan dan Pendampingan yaitu dengan di bentuknya Forum Group Discussion, dan ketiga adalah Evaluasi. Adapun hasil dari pelatihan ini adalah bahwa pengetahuan peserta pelatihan mengenai UMKM berbasis online semakin meningkat. Selain itu pemateri juga memberikan usulan yang sangat potensial untuk perkembangan Desa Lambangsari yaitu model bisnis sharing ekonomi dengan membuat marketplace, yang didalamnya akan menjual produk UMKM binaan dari Desa Lambangsari, tentunya dengan menyesuaikan kebutuhan pasar. Pembicara juga memberikan saran untuk menjalankan bisnis diatas adalah dengan membentuk inkubator bisnis, yaitu dengan urung dana dari masyarakat Desa Lambangsari serta mengedukasi, sosialisasi ke semua Pihak termasuk dengan melibatkan masyarakat, pemerintah, swasta, pengusaha dan para profesional lainnya.
\end{abstract}

Kata Kunci: UMKM, Pelatihan UMKM, Pelatihan Berbasis Online

Abstrak

This community service article discusses the process of online-based MSME training activities at the Lampung Village government office. The implementation of the Online-Based MSME Training activity was attended by 30 (thirty) Participants, located at the Village Government Office of Lambangsari Village, Tambun Selatan District, Bekasi Regency. This implementation was carried out in accordance with the Covid-19 health protocol. The theme of this training is "UMKM Upgrading". The method used in this training is the first preparation and socialization, namely by providing material by the speaker, the second training and mentoring is in the form of a group discussion forum, and the third is evaluation. The result of this training is that the knowledge of the training participants about online-based MSMEs is increasing. In addition, the speaker also gave a very potential proposal for the development of Lambangsari Village, namely a sharing economy business model by creating a marketplace, in which it will sell MSME products fostered from Lambangsari Village, of course by adjusting to market needs. The speaker also gave suggestions for running the above business by establishing a business incubator, namely by refusing to fund funds from the Lambangsari Village community as well as educating, socializing to all parties including by involving the community, government, private sector, entrepreneurs and other professionals.

Keywords: MSMEs, MSME Training, Online-Based Training

\section{PENDAHULUAN}

Salah satu sektor terpenting dalam perekonomian Nasional adalah UMKM. Karena ketika dalam suatu negara mengalami krisis maka UMKM lah sebagai penopang perekonomian negara tersebut. Seperti pada tahun 1998, banyak usaha yang skalanya besar mengalami kebangkrutan dan pada saat itu UMKM lah yang terbukti memiliki daya tahan yang kuat dalam menghadapi krisis perekomomian pada saat itu.

UMKM itu sendiri adalah Usaha Mikro Kecil dan Menengah, yaitu kegiatan ekonomi rakyat yang memiliki kekayaan bersih maksimal 200.000.000,- dimana tanah dan bangunan tempat 
usaha tidak diperhitungkan. Atau mereka yang punya omset penjualan tahunan paling banyak Rp. 1.000.000.000 dan milik warga negara Indonesia (M. Kwartono: 2007).

Menurut Undang-undang Nomor 20 Tahun 2008, UMKM di kelompokkan menjadi tiga kriteria, yaitu sebagai berikut:

1. Usaha mikro

Suatu usaha masuk dalam kriteria usaha mikro apabila badan usaha tersebut memiliki omset atau kekayaan bersih mencapai Rp 50.000.000,- tidak termasuk bangunan dan tanah. Selain itu, hasil dari penjualan usaha mikro tersebut harus mencapai minimal Rp. 300.000.000,- dalam jangka satu tahun. Itulah usaha yang masuk dalam kriteria usaha mikro dan kriteria dari UMKM yang lainnya akan di bahas selanjutnya.

2. Usaha Kecil

Suatu usaha dikatakan usaha kecil apabila usaha tersebut memiliki kekayaan yang bersih mencapai Rp 50.000.000,- dengan kebutuhan yang dipakai maksimal Rp 500.000.000,-. Hasil penjualan yang didapat selama satu tahun mencapai minimal Rp 300.000.000,- dan maksimal Rp 2.500.000.000,-.

3. Usaha Menengah

Suatu Usaha dikatakan usaha menengah apabila aset mulai 500juta sampai degnan 10 miliar, serta penjualan 2,5 miliar sampai dengan 50 miliar. Aset disini tidak termasuk tanah dan bangunan.

Dengan adanya UMKM sebagai penggerak roda perekonomian nasional terbukti sangat berkontribusi dan perannya dalam menyerap tenaga kerja lebih banyak dibanding bisnis lainnya, dengan demikian bahwa UMKM dapat menekan jumlah angka pengangguran dan kemiskinan (Haryadi, RN. Et al: 2021). Sedangkan dalam UMKM sering tidak adanya perencanaan dengan baik, sedangkan Perencanaan yang menjadi salah satu kelemahan para pelaku usaha kecil dan menengah. Karena seringkali para pelaku usaha kecil dan menengah hanya merumuskan apa yang akan terjadi saat ini, sedangkan dalam melakukan usaha kita juga harus merumuskan apa yang akan kita lakukan di masa datang, sehingga usaha akan terus tumbuh dan berkembang (Kumala D : 2021).

Karena hal tersebut, maka diperlukan terobosan-terobosan terbaru dalam mengembangkan UMKM, salah satunya adalah dengan memanfaatkan teknologi, maka dilaksanakanlah Pelatihan UMKM Berbasis Online Di Kantor Pemerintahan Desa Lambangsari Kecamatan Tambun Selatan Kabupaten Bekasi

\section{METODE PELAKSANAAN}

Dalam pelaksanaan kegiatan Pelatihan UMKM Berbasis Online ini berlangsung tanggal 9 November 2021, dengan dihadiri 30 (tiga puluh) Peserta pelaku Usaha warga Desa Lambangsari Kecamatan Tambun Selatan Kabupaten Bekasi. Bertempat di Kantor Pemerintahan Desa Lambangsari Kecamatan Tambun Selatan Kabupaten Bekasi. Pelaksanaan ini diadakan dengan protokol kesehatan Covid-19.

Adapun tema yang di usung dalam pelatihan ini adalah "UMKM Naik Kelas", metode pendekatan yang digunakan dalam pelaksanaan program ini, adalah:

1. Sosialisasi dan Persiapan kepada peserta pelatihan berupa pemaparan materi kepada peserta terkait dengan Apa itu UMKM?, Kategori UMKM, dan Apa yang dimaksud dengan UMKM Naik Kelas dan bagaimana caranya menjadi UMKM Naik Kelas. Selain itu pelatihan ini juga mensosialisasikan bagaimana penggunaan fasilitas digital dan memanfaatkan Perkembangan teknologi agar dapat memasarkan produknya secara luas. Adapun Pembicara yang mengisi sesi ini adalah Bapak Taufik Hidayat, S.EI.,M.Ak.

Beberapa Materi Pelatihan UMKM berbasis Online ini agar dapat dimanfaatkan dengan maksimal oleh semua peserta pelatihan dan dapat dilihat pada tabel dibawah ini: 
Table 1. Materi Pelatihan

\begin{tabular}{|c|c|c|c|c|}
\hline No & Materi Pelatihan & Pembahasan & Jumlah Jam & Tujuan \\
\hline $\mathbf{1}$ & $\begin{array}{c}\text { Pengenalan } \\
\text { UMKM berbasis } \\
\text { Online }\end{array}$ & $\begin{array}{c}\text { Apa itu UMKM?, Kategori } \\
\text { UMKM }\end{array}$ & 30 menit & $\begin{array}{c}\text { Peserta Program dapat memahami } \\
\text { Apa itu UMKM?, Kategori UMKM. }\end{array}$ \\
\hline $\mathbf{2}$ & $\begin{array}{c}\text { UMKM Naik Kelas } \\
\mathbf{3}\end{array}$ & $\begin{array}{c}\text { Apa yang dimaksud dengan } \\
\text { UMKM Naik Kelas dan } \\
\text { bagaimana caranya menjadi } \\
\text { UMKM Naik Kelas }\end{array}$ & 1 Jam & $\begin{array}{c}\text { Peserta Program dapat memahami } \\
\text { Apa yang dimaksud dengan UMKM } \\
\text { Naik Kelas dan bagaimana caranya } \\
\text { menjadi UMKM Naik Kelas }\end{array}$ \\
\hline $\mathbf{4}$ & $\begin{array}{c}\text { Online } \\
\text { Pelatihan UMKM } \\
\text { berbasis Online }\end{array}$ & $\begin{array}{c}\text { Forum Group Discussion } \\
\text { (FGD) saat pelatihan } \\
\text { UMKM berbasis Online }\end{array}$ & 2 Jam & $\begin{array}{c}\text { Peserta program dapat } \\
\text { Berkolaborasi mengenai usaha } \\
\text { yang dijalankan }\end{array}$ \\
\hline
\end{tabular}

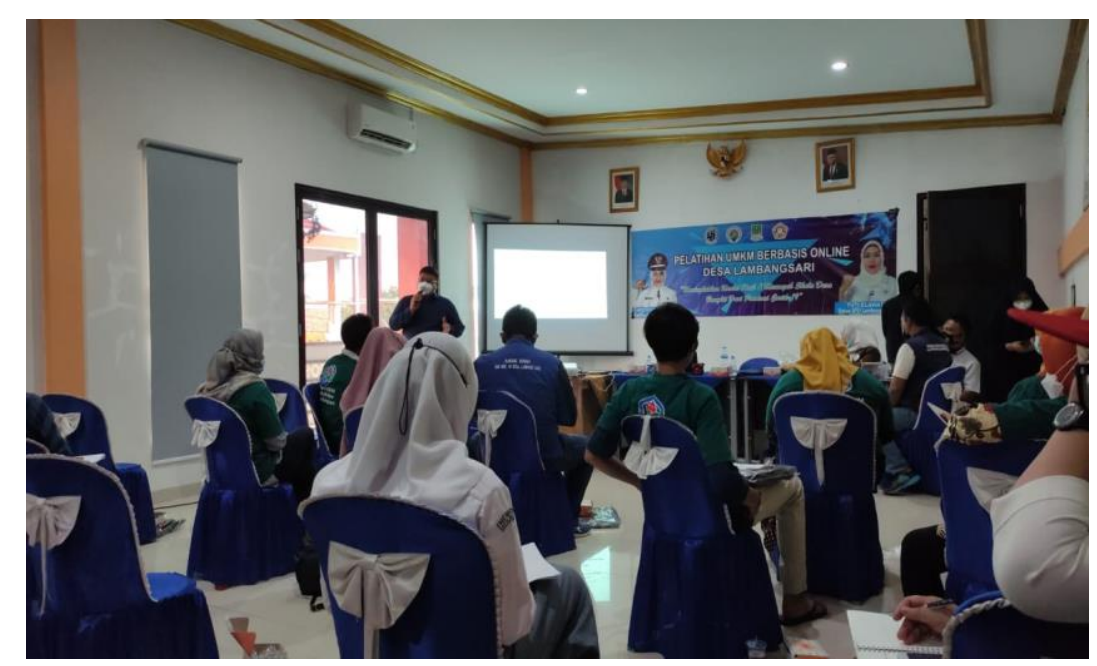

Figure 1 Dokumentasi Pemaparan Materi Pelatihan

\section{Pelatihan dan Pendampingan}

Setelah Materi disampaikan, dilanjutkan dengan simulasi Praktek Kolaborasi, pada sesi ini masing-masing peserta membuat kelompok dengan komposisi 1 kelompok 5 orang. 1 kelompok terdiri dari kelas mikro tunas, bermbang dan mekar. Untuk kelompok diberikan waktu 10 menit untuk sharing tentang usahanya kepada teman-teman di kelompoknya dan mencari seseuatu yang bisa dikolaborasikan/ disinergikan dengan teman sekelompoknya. Tetapi jika dalam kelompok tersebut belum bisa ada yang dikolaborasikan maka boleh mencari kelompok lain untuk mensinergikan usahanya.

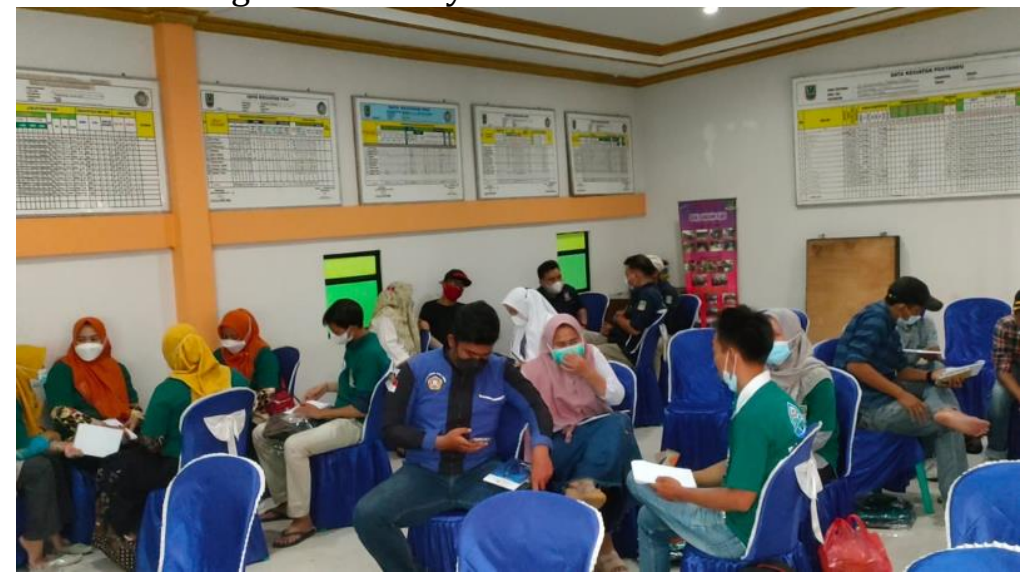

Figure 2 FGD Pelatihan UMKM Barbasis Online 


\section{HASIL DAN PEMBAHASAN}

Adapun pelatihan yang telah dilakukan oleh tim pengabdian kepada masyarakat ini adalah Pada pelatihan sesi pertama dilakukan penyampaian materi tentang UMKM, definisi UMKM, Kategori UMKM, dan Apa yang dimaksud dengan UMKM Naik Kelas dan bagaimana caranya menjadi UMKM Naik Kelas. Selain itu pelatihan ini juga mensosialisasikan bagaimana penggunaan fasilitas digital dan memanfaatkan Perkembangan teknologi agar dapat memasarkan produknya secara luas.

Sedangkan pada sesi kedua dibentuk Forum Grup Discussion, untuk simulasi Praktek Kolaborasi, pada sesi ini masing-masing peserta membuat kelompok dengan komposisi 1 kelompok 5 orang. 1 kelompok terdiri dari kelas mikro tunas, bermbang dan mekar. Untuk kelompok diberikan waktu 10 menit untuk sharing tentang usahanya kepada teman-teman di kelompoknya dan mencari seseuatu yang bisa dikolaborasikan/ disinergikan dengan teman sekelompoknya. Tetapi jika dalam kelompok tersebut belum bisa ada yang dikolaborasikan maka boleh mencari kelompok lain untuk mensinergikan usahanya

Sesi selanjutnya adalah evaluasi dari pemateri. Dimana pemateri memaparkan bahwa dalam model bisnis, terdapat Sharing Ekonomi, dimana seorang pelaku usaha dapat berbagi barang dan jasa yang difasilitasi oleh saluran digital dan internet, baik secara gratis ataupun dengan membayar fee. Selanjutnya pemateri memberikan usulan simulasi potensi bisnis untuk desa, yang tergambar sebagai berikut:

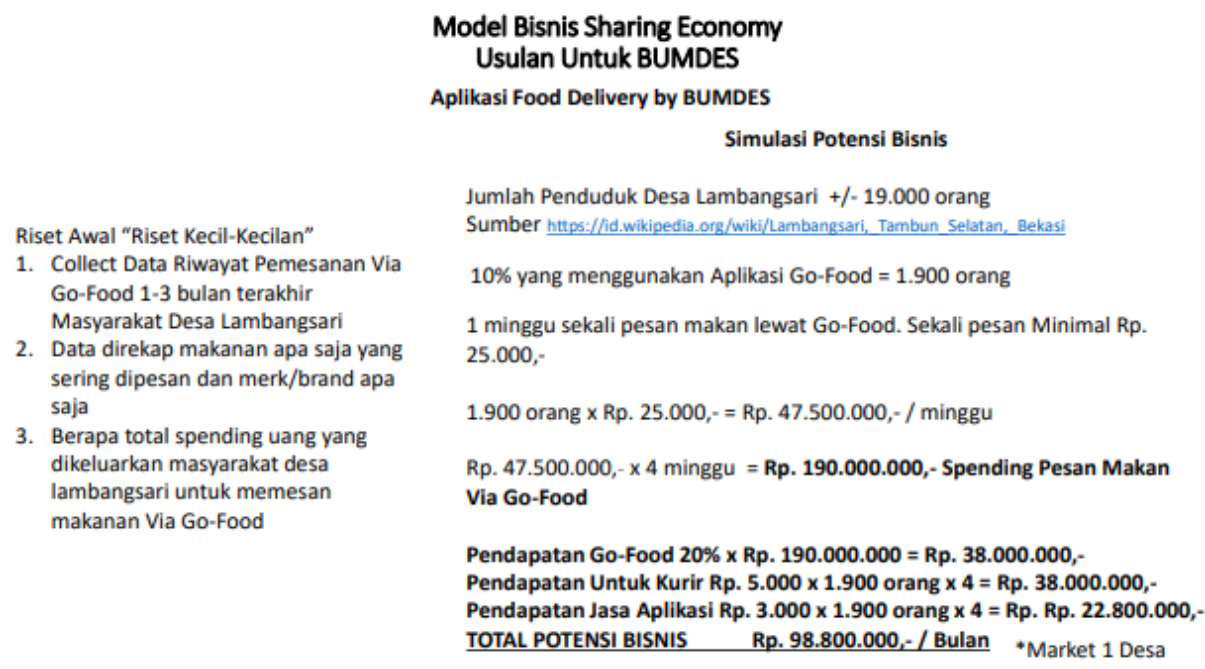

Figure 3 Model Bussines Sharing Economy

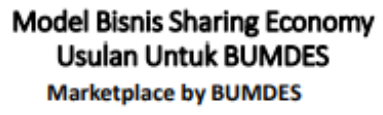

Riset Awal "Riset Kecil-Kecilan"

1. Collect Data Riwayat Belanja Online Via Marketplace/Medsos Masyarakat Desa Lambangsari

2. Data direkap produk-prduk apa saja yang sering dibeli dan merk/brand apa saja

3. Berapa total spending uang yang dikeluarkan masyarakat desa Lambangsari untuk belanja online

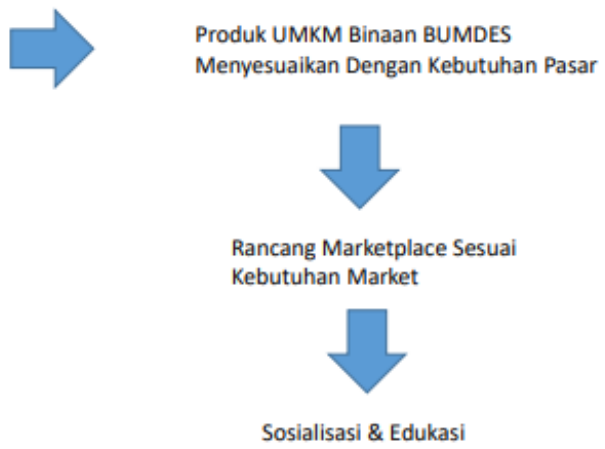

Figure 4 Usulan Model Bussiness 




Figure 5 Dokumentasi Pelatihan UMKM berbasis Online

\section{KESIMPULAN}

Pengetahuan peserta dalam hal ini warga Desa Lambangsari Kecamatan Tambun Selatan mengenai UMKM berbasis Online sebelum adanya kegiatan ini mayoritas berada di kategori kurang memahami. Tetapi setelah diadakannya kegiatan ini. Diketahui bahwa pengetahuan peserta pelatihan mengenai UMKM berbasis online semakin meningkat. Selain itu pemateri juga memberikan usulan yang sangat potensial untuk perkembangan Desa Lambangsari yaitu model bisnis sharing ekonomi dengan membuat marketplace, yang didalamnya akan menjual produk UMKM binaan dari Desa Lambangsari, tentunya dengan menyesuaikan kebutuhan pasar.

Pembicara juga memberikan saran untuk menjalankan bisnis diatas adalah dengan membentuk inkubator bisnis, yaitu dengan urung dana dari masyarakat Desa Lambangsari serta mengedukasi, sosialisasi ke semua Pihak termasuk dengan melibatkan masyarakat, pemerintah, swasta, pengusaha dan para profesional lainnya.

\section{REFERENSI}

Adi, M Kwartono. 2007. Analisis Usaha Kecil dan Menengah. Yogyakarta: Andi Offset. Undangundang Nomor 20 Tahun 2008

Effendy, A. A., \& Sunarsi, D. (2020). Persepsi Mahasiswa Terhadap Kemampuan Dalam Mendirikan UMKM Dan Efektivitas Promosi Melalui Online Di Kota Tangerang Selatan. Jurnal Ilmiah MEA (Manajemen, Ekonomi, \& Akuntansi), 4(3), 702-714.

Haryadi, R. N., Anda Rojali, Khumidin, \& M. Fauzan. (2021). Sosialisasi Penggunaan Online Shop berbasis Website di UMKM Cimanggis. Jurnal Pengabdian Masyarakat Madani (JPMM), 1(1), 10-16. https://doi.org/10.51805/jpmm.v1i1.3

Kumala, D., Yesi Novianti, Supriatal, \& Novia Safitri. (2021). Pelatihan Kewirausahaan dan Pemasaran bagi Pengurus Koperasi Usaha Kecil dan Menengah di Kelurahan Tugu Cimanggis. Jurnal Pengabdian Masyarakat Madani (JPMM), 1(1), 6-9. https://doi.org/10.51805/jpmm.v1i1.2 (Original work published July 15, 2021). 